\title{
A research on the effectiveness of agricultural water rights allocation based on market orientation
}

\author{
Kanglei $\mathrm{Bi}^{1}$, Lili Rong $^{1, *}$ \\ ${ }^{1}$ Business School, University of Jinan, Jinan, 250002 Shandong, China
}

\begin{abstract}
There are some problems in China's agricultural water resources, such as low per capita consumption and uneven spatial and temporal distribution. It is urgent to speed up the reform of water rights trading mode. Based on the market orientation and the experience of the United States and Australia, this paper studies the effectiveness of China's agricultural water rights trade. Firstly, the characteristics of "quasi-market" should be clarified. Secondly, under the market mechanism, this paper analyzes the mechanism of the impact of economic incentives of trading subjects, reasonable delimitation of trading prices and multiple participation of institutions and departments. Furthermore, the factors that affect the efficiency are deeply analyzed. At last, the paper provides some suggestions on the construction of a trading mechanism with Chinese characteristics from the aspects of right confirmation registration, pricing mechanism and supervision regulations, to provide decision support for agricultural water rights management system.
\end{abstract}

\section{Introduction}

Since the 21 st century, the shortage of water resources has become an increasingly severe challenge facing mankind. Facing the changes of the new era, it is of great strategic significance to affirm the rights of water resources with public attributes and develop a sustainable water rights trading system, especially under the circumstances of future uncertainty and water supply risks. This can improves economic efficiency and production efficiency. but also improves the allocating efficiency of water resources flowing to the environment ${ }^{[1]}$. The use of agricultural water is the most important way to utilize water resources in China at present, but there are still many problems such as surplus of agricultural water and low utilization rate. How to effectively implement the agricultural water right transaction to improve its water use efficiency has important practical value. Based on this, this paper, from the perspective of water rights trading, explores the practical effectiveness of agricultural water rights market and provides systematic reference for China's water rights trading management.

\section{Research trends}

In the 1980s and 1990s, the international community began to pay attention to the utilization of agricultural irrigation water. At the beginning of this century, it was gradually turned to the research on the management performance of water resources and sustainable development, and the discussion on water rights trading model and renewable energy issues was also increased ${ }^{[2]}$. Aiming at how to effectively balance water resources among different economic sectors, Qian Dang, Megan Konar (2016) proposed a sustainable water rights trading model, and conducted research from the aspects of profit maximization, trading risks and target taxes in order to make agricultural water rights trading more effective $\mathrm{e}^{[3]}$. Thanh Mai (2019) innovatively put forward a systematic water rights trading model on the basis of previous studies, and discussed the uncertainty and complexity of the water rights trading system ${ }^{[4]}$. In the domestic research, Wang Shucheng (2000) pointed out earlier that under the new conditions market-oriented economy, we should actively explore the water rights system and the market mechanism of water rights trading ${ }^{[5]}$. Wang Yahua (2007) pointed out that the root of the existence of water market lies in the imbalance of distribution and utilization of water resources ${ }^{[6]}$. Hu Jilian (2004) proposed the market allocation model of water rights when studying the Yellow River Basin ${ }^{[7]}$; Moreover, from the perspective of exclusiveness of property rights, the importance of defining the water rights of national ownership of water resources, water intake rights and water use rights of end farmers is put forward, and the role of the Farmers' Water Users Association in China is affirmed $^{[8]}$. It has laid the foundation for market transactions of agricultural water rights. The agricultural water rights trade is mainly to meet the development needs of industry and cities and to carry out interdepartmental and inter-industry trade, except among farmers in the river basin. Jiang Donghui (2011) believes that the market-oriented circulation of agricultural water rights improves the allocation efficiency of water resources thus producing obvious comprehensive social benefits ${ }^{[9]}$. Different trading modes play an important role in promoting agricultural water rights market transactions. Zheng Zhilai (2017) proposed that the add

\footnotetext{
* Corresponding author: $\operatorname{lrg518@126.com}$
} 
demand of water can be met through the replacement mode of agricultural water right in water shortage $\operatorname{areas}^{[10]}$. Price mechanism is also one of the core contents of market construction of water rights. The determination of water right transaction price mainly includes traditional pricing methods such as full cost method, shadow price method etc. Tian Guiliang (2019) pointed out that the market should play a decisive role in the price schedule of water rights transactions. Based on the full cost price, the market should be taken as a guide, and a negotiated pricing model and a bidding model for water rights in the region should be established ${ }^{[11]}$. However, Xu Changxin (2019) pointed out that the information asymmetry in China's water rights market has led to the actual pricing of water rights being higher than the benchmark pricing, affecting the trading activity in the water rights market, thus affecting the rational allocation of water resources ${ }^{[12]}$. The successful transaction of agricultural water rights also depends on the joint efforts of the government and the market. Pan Haiying (2018) believes that in the construction of the water rights market with Chinese characteristics, the government should perform its duties in innovating the initial water rights allocation decision-making mechanism, perfecting laws and regulations and market supervision, and promoting the healthy and effective operation of water rights trading ${ }^{[13]}$.

Based on the above research, foreign scholars have put forward different water rights trading models from the implementation of the trading mechanism after the confirmation rights of agricultural water. And domestic scholars put forward the concept of market-oriented trading mechanism in China, and then further studied the trading mode and the corresponding pricing mechanism on the basis of it. However, for the current situation of water resources in our country, the market-oriented trade of agricultural water rights may need further investigation. Starting from the market orientation, this paper studies the practice of water rights market transactions in the United States and Australia, and explores the effectiveness of market transactions of agricultural water rights It also defines the influencing factors of market-oriented water rights transactions, and puts forward constructive suggestions based on the actual situation in China.

\section{The practice research of the market transactions of agricultural water rights}

\subsection{Foreign practices}

At present, most countries still rely on administrative means to allocate water resources. Only a dozen countries have established water rights markets in the world. The United States, Australia and other countries have much experience to learn from the construction of the trading market system of water rights. In contrast, for developing countries, despite carrying out the exploration of water rights market, the development of water rights system is slow due to the restriction of local conditions and other objective factors.

\subsubsection{The US water bank system}

The most important form of water right transaction in US is the water bank system, of which California is the most representative. The California government attaches great importance to the marketization of water rights trading. The water bank system was creatively established in 1991. The essence of its operation is a trading intermediary system, which acts as a trading medium and stores, trades and manages water in the form of stock system. And through leasing or resale, water resources will be transferred from the main body with low demand to the main body with high demand. Especially in dry season, it can solve the use problem of water through efficient transactions of water rights by all water rights holders. And with the change of the situation, the California government has also continuously developed the trading mode of agricultural water rights and innovated financial derivatives of water rights.

\subsubsection{Australian water financing and water stock system}

At the beginning of the 21 st century, Australia began to reform towards the market-oriented direction of sustainable water rights trading. And it has been continuing to mature. The most famous water rights trading system is the "water rights trading" and "water financing" system adopted by NSW in Murray-Darling basin, and it has prominent influence on the registration of water rights permits for groundwater and surface water, unit share structure etc. In 2007, Victoria carried out the reform of water rights system and innovatively put forward the water stock system. Water stock makes water right itself a tradable commodity, and makes water resource or water right have clear property right attribute and tradable product attribute, which expands the profitability and liquidity of the transaction and has important practical significance for the market reform of agricultural water rights.

\subsection{Domestic situation}

\subsubsection{China practices}

On June 14, 2017, the People's Bank of China and other seven departments jointly issued the overall plan for the green finance reform and innovation pilot areas in Zhejiang, Jiangxi, Guangdong etc. They explicitly took emission rights and water rights as the innovation elements of green finance reform. It can be seen that the government plays an important guiding and encouraging role in promoting the market transaction of water rights. At present, in China, in addition to the China Water Rights Exchange, a national exchange, some sporadic water rights trading platforms have also been established, such as the Shiyang River Basin Water Rights Trading Center, which provides trading introduction, trading inquiry and other functions for water rights trading, and timely releases details and market dynamics of water 
rights trading. In addition, Xinjiang Qitai County Water Rights (Quantity) Trading Center etc, are also continuously exploring the market transactions of agricultural water rights. However, at present, a systematic marketization system of agricultural water rights has not been established, and its development is slow due to its inherent nature.

\subsubsection{The derivation of an argument}

The ultimate goal of water rights trading is to achieve water rights trading. The water rights trading in China should not only conform to the basic national conditions of water resources, but also conform to the requirements of water resources management. Therefore, the study of the market transactions of agricultural water rights must first be clear:

First, the object of water market. The Water Law clearly in China stipulates that the water in reservoirs built and managed by rural collective economic organizations shall be used by the rural collective economy and they have the right to use and transfer. When surplus water resources from farmers' irrigation areas enter the market for trading, the first issue involved is the confirmation of rights, that is, the clarification of the relationship between agricultural water rights. In addition, we should realize that water is a valuable commodity, which provides conditions for entering the market.

Second, the characteristics of "quasi-market". At present, it is generally believed that the market transactions of agricultural water rights has the characteristics of "quasi-market". Due to the great differences between different watersheds and different users, competitive water resources cannot be completely allocated by market mechanism or government monopoly. That is also helpful to realize the optimal configuration and sustainable utilization of water resources, so it promotes the economic development of river basin and irrigation areas and maintain the ecological security of the country.

As the market can gather the buying and selling wishes and make use of the liquidity of the trading platform, the agricultural water rights can be effectively transferred between different time, regions and industries, and the resources can be effectively allocated. This paper chooses the research perspective of "transaction" to carry out effective research on the marketization mechanism of agricultural water rights.

\section{The validity analysis of the market transactions of agricultural water rights}

\subsection{The efficiency analysis of agricultural water rights trading mechanism}

Coase Theorem clearly states that the property right system should include two levels and key links: the initial distribution and confirmation of the property right of resources in the primary market, the market transaction mechanism after resource property right distribution in secondary market. In reality, the agricultural water right has the property right of township clubs, which weakens the exclusive rights and inhibits the transfer of water rights. The market transaction analysis of agricultural water rights is shown in Fig. 1. Its economic incentives, transaction prices and multiple participation of financial institutions play an important role in improving transaction efficiency.

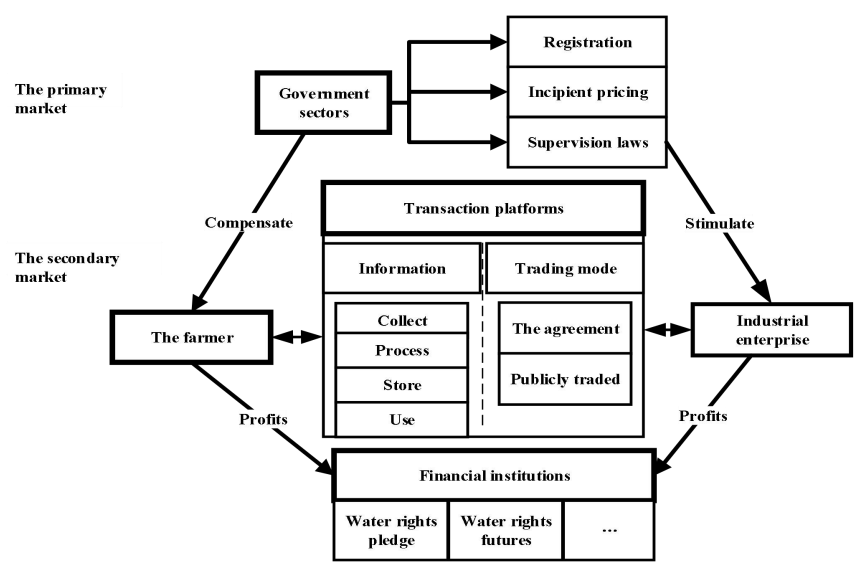

Fig. 1. The market transaction of agricultural water rights

\subsubsection{Economic incentives for trading subjects}

For the transferor and transferee of water rights with the personality of "economic person", the transaction of agricultural water rights entering the market has certain economic incentive effect. The two sides directly exchange supply and demand information on the virtual trading platform provided by the market, thus it saves the time cost and searching cost of transaction. At the same time, driven by interests, it has greatly improved the enthusiasm of farmers and water-using enterprises to save water. Generally speaking, the water rights trading platform can promote the prosperity and development of the water rights market in terms of the release of trading information, gathering of water rights trading subjects, trade matching and demonstration.

\subsubsection{Reasonable delineation of transaction price}

China is facing the dilemma that water resources shortage and waste coexist. Transaction price and transaction cost are the core factors that affect the efficiency. The government should give more power to the market so that prices are affected by the relationship between supply and demand and truly reflect the intrinsic value, thus giving full play to the role of the market in stimulating the enthusiasm of trading subjects. Agricultural water rights trading enters the market and plays a leverage driving role, which is more in line with the interests of all stakeholders, thus it regulates effectively the relationship between the supply and demand of water.

\subsubsection{Multiple participation of financial institutions}


Traditional water rights trading is path-dependent, which affects the integrity and transparency of the market. As the agricultural water right has the property ownership attribute, it can be regarded as a kind of "capital" to a certain extent, and market transactions are conducive to opening up participation paths for financial institutions. Through innovative trading forms such as lease and pledge of water rights, futures trading, investment and financing channels will be innovated to further tap the trading potential and economic value of it. On the basis of market-oriented trading platform, financial support promotes the reform of the market transactions of it, which plays a positive role in forming the awareness of water-saving and protecting the environment.

\subsection{The analysis about comparing by the traditional trade form of agricultural water rights}

The traditional trade of agricultural water rights is mainly carried out by the government and assisted by the water resources associations. The comparison analysis of the two modes is made, which provides theoretical support for better development.

\subsubsection{Advantages and disadvantages of the market transactions of agricultural water rights}

First of all, the agricultural water rights market provides an effective and open trading platform for suppliers and demanders, which breaks through the time and space restrictions. Trading water rights in the market is also conducive to bringing its scale benefits into play and reducing transaction costs to a certain extent. Secondly, the information disclosure of both parties to the water rights transaction in the effective market not only reduces the information asymmetry, but also plays a positive role in reducing transaction costs such as the cost of search and negotiation. What is important is that the market has the function of price discovery for agricultural water rights trading. However, while financial institutions develop trading methods, improve trading efficiency and obtain economic benefits, the corresponding trading risks also rise.

\subsubsection{Advantages and disadvantages of traditional trade of agricultural water rights}

The traditional trade of agricultural water rights is mainly conducted by the government and has certain monopoly. This way of resource configuration is inefficient to some degree, which not only severely dampens the enthusiasm of water rights suppliers due to the lack of effective incentive mechanism, but also highlights the low efficiency and rent-seeking activities caused by administrative "flat regulation" in the process of water rights transition. Historical experience tells us that "flat regulation" stifles efficiency. The transfer-out party and the transfer-in party have lost the internal incentive to save water, causing serious waste of water resources $^{[14]}$. Moreover, it is difficult for the government-led agricultural water rights transaction to form competitive water rights transaction prices, which leads to price imbalance.

\section{Influencing factors of operational efficiency of agricultural water rights market}

The market transactions of agricultural water rights is not achieved overnight, and the main influencing factors are different in the early, middle and late stages. In the initial stage, the primary market plays an important role, and factors such as assessment of hydrological characteristic capacity, arrangement of property rights, and improvement of legislation plan have important influence. In the medium term, potential income, transaction costs and transaction charges are important factors that affect the healthy operation of the secondary market. In the later period, the expansion of new markets, new trading modes, innovation and externalities of emerging products of water play an important role Generally speaking, its operation efficiency cannot be separated from the four main factors: property right relation, transaction cost and legal system.

\subsection{Unclear property right relations}

The water right as the object is gradually recognized for its certain property, thus entering the market for trading. However, as the subject of agricultural water right trading, the definition is unclear, and the confirmation and protection are relatively lagging behind. Theoretically, the right to water belongs to the state or the collective, in essence to the local or relevant departments. The subject of agricultural water rights is nominal. Moreover, the initial property rights of water users in counties, townships, villages and irrigation districts have not yet been clearly allocated, which is a mere formality. This has seriously affected the effective operation of the agricultural water rights market.

\subsection{Relatively high transaction costs}

Transaction costs and chargers are important factors that affect the configuration efficiency of agricultural water rights and realize the sustainable development of the market transactions of agricultural water rights. Through innovative transaction forms such as water rights lease and pledge, water rights real option, futures transaction, etc., it brings into play brokerage and service functions, and further explores the market potential and economic value of agricultural water rights. However, at present, the infrastructure of the market transactions is not perfect and there are relatively large transaction costs. In addition, the unreasonable pricing mechanism, the price formed spontaneously by the market is unfair. In the long run, this will affect the trading efficiency of the agricultural water rights market.

\subsection{Inadequate legal system}


Agricultural water rights enter the market to trade, which challenges the traditional water law system. As to how to maintain and protect the order of water rights trading, avoid speculation and arbitrage, drive up water prices and damage the interests of third parties, the lack of reasonable legal norms has affected the orderly conduct of agricultural water rights trading. At the same time, in the process of water rights market operation, it is inevitable that infringement will disturb the market order. The lack of corresponding legal system makes it difficult to guarantee the interests of all parties involved in the transaction, the transaction safety is threatened, and the operation efficiency will be greatly reduced.

\section{Recommendations}

The registration system for the confirmation of rights is the foundation and premise of agricultural water right transaction. On the basis of improving the level of monitoring and metering technology for agricultural water, the registration system for the confirmation of rights should be fixed to provide basic guarantee for the market transactions of agricultural water right. So as to play the leverage of the market to improve the efficiency of agricultural water rights trading, realize the property income of water rights holders such as farmers, and truly realize the efficient development of water rights trading.

Price is an indicator of the relationship of supply and demand for goods. Transaction price is the core factor that affects efficiency. The pricing power of transactions should be given more to the market, so that the price is affected by both of supply and demand to truly reflect its intrinsic value. So it can give full play to the role of the market in stimulating the enthusiasm of trading subjects. Agricultural water rights trading enters the market to play a part in the market leverage, which is more inure to the benefit of all stakeholders. Thus it also effectively regulate the relationship between the supply and the demand of water right and optimizing the effective management of water resources.

The government should strictly exercise the functions of administrative law enforcement of water sources, introduce a third-party supervision mechanism, and prohibit abuse of power and corruption in the process of transactions. For innovative market trading methods, relevant laws and regulations should be formulated to protect the interests of third parties, not at the cost of damaging the environment. At the same time, solutions to trading disputes and conflicts should be clarified. International experience also shows that legal construction is the core guarantee for water rights trading. Constantly strengthen the legal support for water rights trading, so it is conducive to establish an agricultural water rights trading market with Chinese characteristics.

Fund Project: National Social Science Project "research on the large-scale transaction and its effect of right-tohousehold agricultural water right" (18BJY075)

\section{References}

1. A. C. HORNE, E. L. O'DONNELL, A. J. LOCH, et al, Environmental water efficiency: Maximizing benefits and minimizing costs of environmental water use and management. J. Wiley Interdisciplinary Reviews: Water. 5,4:e1285 (2018)

2. Y. H. Wang, Q. F. Shu, J. Z. Wu, A Review of Water Rights Market Studies and a Prospect of Research on Chinese Water Rights Market. J. China population, Resources and Environment. 27, 6:87-100 (2017)

3. D. QIAN, K. MEGAN, et al, A theoretical model of water and trade. J. Advances in Water Resources. 89:3241 (2016)

4. T. MAI, S. MUSHTAQ, A. LOCH, et al, A systems thinking approach to water trade: Finding leverage for sustainable development. J. Land Use Policy. 82:595608 (2019)

5. S. C. Wang, Water Right and Water Market-Economic Measures to Realize Optimal Configuration of Water Resources. J. China Water Resources. 11:6-9 (2000)

6. Y. H. Wang, Comments on the reform of water price, water right and water market in China. J. china population resources and environment. 05: 153-158 (2007)

7. J. L. Hu, Y. X. Ge, Distribution Mode and Coordination Mechanism of Yellow River Water Resources-And on Construction and Management of Yellow River Water Rights Market. J. Management World. 08: 43-52 (2004)

8. J. L. Hu, Definition, implementation efficiency and improvement strategies of agricultural water right. $\mathrm{j}$. Issues in Agricultural Economic. 31, 11: 40-46 (2010)

9. D. H. Jiang, X. Jin, J. L. Hu, Study on the Marketization of Agricultural Water Rights and Its Application Strategies. J. Issues in Agricultural Economic. 35, 12: $42-47$ (2011)

10. Z. L. Zheng, S. Hu, A Empirical Study on Different Investment Models of Agricultural Water Rights Replacement under the Background of Land Circulation. J. Rural Economy. 7:110-114 (2017)

11. G. L. Tian, Y. C. Hu, Models for Differential Pricing for Bulk Water Rights Trading. J. Resources Science. 41,2:313-325 (2019)

12. C. X. Xu, L. H. Yang, A Analysis of Information Asymmetry in China's Water Rights Trading Market. J. China population, Resources and Environment. 29, 9: 127-135 (2019)

13. H. Y. Pan, X. D. Ye, Government Action for Water Rights Market Construction: An Overall Framework. J. Reform. 1: 95-105 (2018)

14. H. G. Huang, L. L. Rong, J. L. Hu, Study on Market Regulation of Agricultural Water Resource Urbanization J. Chinese Journal of Agricultural Resources and Regional Planning. 33, 02:45-50 (2012) 